\title{
КОМПЬЮТЕРНОЕ МОДЕЛИРОВАНИЕ КАК ОДИН ИЗ КОМПОНЕНТОВ ВНЕУРОЧНОЙ ДЕЯТЕЛЬНОСТИ ПО ХИМИИ В СТАРШЕЙ ШКОЛЕ
}

\author{
И. А. Шабанова, С. В. Ковалева, О. Х. Полещук, А. В. Фатеев \\ Томский государственный педагогический университет, Томск
}

\begin{abstract}
Анализируется понятие «внеурочная деятельность» в школьном образовании. Охарактеризованы особенности внеурочной деятельности. Приведено понятие «внеурочная деятельность по химии», выделена ее цель и специфическая особенность на старшей ступени обучения в современной школе. Обоснована необходимость выполнения проектов по химии. Предложено одно из актуальных направлений: деятельность обучающихся по моделированию строения веществ. Описана методика работы обучающихся с программами Gaussian и GaussView, используемыми для решения задач квантово-механического моделирования молекулярных структур. Дана характеристика индивидуальным проектам по химии, приведены этапы их выполнения. Показан пример построения обучающимися молекулярных структур хлоридов 15-й группы периодической системы. Представлены результаты оценивания выполненных проектов на основе разработанных критериев и анкетирования с целью определения отношения обучающихся к компьютерному моделированию молекул.
\end{abstract}

Ключевые слова: внеурочная деятельность по химии, проектная деятельность, этапы выполнения проекта, оценивание проекта, компьютерное моделирование, квантово-химические расчеты.

В современном школьном образовании внеурочная деятельность является одним из компонентов образовательного процесса и имеет обязательный характер для обучающихся [1]. Она организуется с целью удовлетворения потребностей учащихся в познавательной деятельности, содержательном досуге, их участия в общественно полезной деятельности и самоуправлении $[1,2]$.

Внеурочная деятельность учащихся - деятельность, которая осуществляется во внеурочное время в целостной взаимосвязи с другими формами организации обучения, направленная на достижение личностных, метапредметных и предметных результатов, сформулированных в федеральном государственном образовательном стандарте нового поколения [2]. Для этой деятельности характерны специфические особенности, которые выделены нами на основе анализа нормативной и методической литературы [1-8]:

- проводится вне учебного расписания образовательного учреждения;

- осуществляется в рамках образовательной программы школы в соответствии с разделом «Внеурочная деятельность»;

- составляется специальная программа, разработанная учителем-предметником и утвержденная руководителем школы;

- проводятся занятия продолжительностью от 1,5 до 3,5 часов в неделю;

- позволяет решать широкий спектр задач обучения, воспитания, развития и оздоровления школьников за пределами урока и охватывает содержание всех школьных предметов, в том числе и химии;

- имеет переменный состав учащихся и зависит от их потребности в данном виде деятельности. 
Понятие «внеурочная деятельность по химии» введено Д. С. Исаевым и М. С. Пак и сформулировано следующим образом: «Внеурочная деятельность по химии - деятельность, направленная на формирование познавательного интереса школьников к химии, осуществляемая во внеурочное время с учетом современных требований ФГОС нового поколения» $[4$, с. 55]. Целью внеурочной деятельности по химии, исходя из данного определения, является формирование и развитие познавательного интереса по предмету.

Введение внеурочной деятельности на старшей ступени обучения в современной школе имеет специфическую особенность - подготовку и защиту итогового проекта, который может быть выполнен в школе в рамках внутришкольного дополнительного образования или внеурочной деятельности [2, 4]. По мнению авторов [9], итоговый проект по химии представляет собой учебный проект, выполняемый обучающимися в рамках учебного предмета «Химия» с целью демонстрации своих достижений в самостоятельном освоении содержания и методов избранной области знаний и (или) видов деятельности, а также способности проектировать и осуществлять целесообразную и результативную учебно-познавательную, конструкторскую или творческую деятельность [9, с. 54]. В связи с этим возникает необходимость разработки тематики и содержания проектов по химии для 10-11-х классов.

Одним из актуальных направлений внеурочной деятельности обучающихся по химии является компьютерное моделирование строения веществ и проведение квантово-химическихе расчетов [10-13]. В настоящее время в науке используется достаточно большое число квантово-химических программ, таких как ChemOfice, Gaussian, HyperChem, Spartan, ADF, GAMESS. Все они позволяют проводить квантово-химические расчеты молекул с анализом их электронной структуры, спектров, термохимических свойств и т. п. [14-18]. Эти программы применяются к различным органическим, неорганическим и координационным соединениям.

Моделирование молекул химических соединений позволяет наглядно показать строение веществ. Для изучения строения и свойств молекул на основе компьютерного моделирования часто используют программы Gaussian и GaussView. Это комплексный программный продукт предназначен для решения задач квантово-механического моделирования атомных и молекулярных структур. Он включает в себя программы, реализующие методы молекулярной механики, квантовой химии и молекулярной динамики $[10$, с. $39 ; 17,18]$. GaussView обладает развитыми средствами визуализации, которые могут применяться как при подготовке структуры молекулы, так и при анализе результатов.

С помощью программного комплекса учащимся можно демонстрировать строение молекул химических соединений, расчеты геометрических и энергетических параметров молекул.

При выполнении проектов обучающимися были использованы программы Gauss View 5.0.8 и Gaussian'03. Подготовительным этапом для выполнения заданий школьниками по проектам является ознакомление с программами Gauss View 5.0.8 и Gaussian’03 [15, 17, 18]. Для этого разработана методика работы с данными программами, после освоения которых школьники строят несложные молекулы веществ, например диоксидов углерода и серы, аммиака, воды и других соединений, выполняют оптимизацию геометрии, определяют геометрические (длины связей, углы между связями) параметры смоделированных молекул. На данном этапе работы большую помощь школьникам оказывает учитель, консультируя и координируя их деятельность, также при этом происходит активная коммуникативная деятельность учащихся внутри группы по освоению программы.

На основе приобретенных знаний и полученных навыков в дальнейшем школьники выполняют индивидуальные проекты по темам, предлагаемым учителем или самими обучающимися $[19,20]$. Примерный перечень тем приведен ниже: 
1. Политионовые кислоты.

2. Полисульфаны и полисульфиды.

3. Оксиды и кислоты фосфора.

4. Гидриды р-элементов.

5. Галогениды р-элементов.

6. Оксиды азота.

После выбора темы проекта учитель совместно с учащимися планирует примерные этапы его выполнения (табл. 1) [20].

Таблица 1

Этапы выполнения проекта

\begin{tabular}{|c|c|c|c|}
\hline \multirow{2}{*}{ Этапы } & \multirow{2}{*}{ Задачи } & \multicolumn{2}{|c|}{ Деятельность } \\
\hline & & обучающихся & педагога \\
\hline $\begin{array}{l}\text { 1. Погружение в про- } \\
\text { ект и его планирова- } \\
\text { ние }\end{array}$ & $\begin{array}{l}\text { Определить тему } \\
\text { проекта, уточнить } \\
\text { цель, выбрать ученика } \\
\text { (по желанию). Сфор- } \\
\text { мулировать задачи, } \\
\text { определить этапы } \\
\text { выполнения проекта } \\
\end{array}$ & $\begin{array}{l}\text { Обсудить тему проекта, его } \\
\text { содержание и спланировать } \\
\text { этапы проекта совместно с } \\
\text { учителем. Уточнить задания } \\
\text { проекта, освоить методику } \\
\text { работы с программой } \\
\text { GaussView 5.0.8 } \\
\end{array}$ & $\begin{array}{l}\text { Мотивировать учащегося, } \\
\text { объяснить цели и задачи } \\
\text { проекта, его содержание и } \\
\text { составить план работы. } \\
\text { Сформулировать задания для } \\
\text { учащегося по работы с про- } \\
\text { граммой GaussView 5.0.8 }\end{array}$ \\
\hline $\begin{array}{l}\text { 2. Выполнение } \\
\text { проекта }\end{array}$ & $\begin{array}{l}\text { Смоделировать } \\
\text { молекулы (ионы) с } \\
\text { использованием } \\
\text { программы Gauss View } \\
5.0 .8 \text { согласно заданию } \\
\text { проекта }\end{array}$ & $\begin{array}{l}\text { Выполнить учебно-исследо- } \\
\text { вательские задания по } \\
\text { моделированию молекул } \\
\text { (ионов) неорганических } \\
\text { веществ. Проанализировать } \\
\text { полученные результаты }\end{array}$ & $\begin{array}{l}\text { Научить с помощью програм- } \\
\text { мы оптимизировать построен- } \\
\text { ные молекулы (ионы) неорга- } \\
\text { нических веществ, рассчитать } \\
\text { длины их связей и углы между } \\
\text { связями в этих молекулах. } \\
\text { Координировать деятельность } \\
\text { обучающегося и консультиро- } \\
\text { вать его по возникающим } \\
\text { вопросам }\end{array}$ \\
\hline $\begin{array}{l}\text { 3. Оформление } \\
\text { полученных резуль- } \\
\text { татов }\end{array}$ & $\begin{array}{l}\text { Проанализировать } \\
\text { полученные результа- } \\
\text { ты моделирования } \\
\text { молекул, выявить } \\
\text { успехи и неудачи } \\
\text { проекта и объяснить } \\
\text { их причины } \\
\end{array}$ & $\begin{array}{l}\text { Обсудить полученные } \\
\text { результаты проекта и провес- } \\
\text { ти самоанализ и самооценку } \\
\text { результатов деятельности. } \\
\text { Оформить результаты } \\
\text { проекта }\end{array}$ & $\begin{array}{l}\text { Оказать помощь при анализе и } \\
\text { оформлении полученных } \\
\text { результатов }\end{array}$ \\
\hline 4. Защита проекта & $\begin{array}{l}\text { Подготовить доклад и } \\
\text { презентацию. } \\
\text { Представить проект на } \\
\text { конференции }\end{array}$ & $\begin{array}{l}\text { Подготовить материалы к } \\
\text { защите проекта и предста- } \\
\text { вить их на конференции }\end{array}$ & $\begin{array}{l}\text { Консультировать школьника } \\
\text { при подготовке материалов к } \\
\text { защите проект }\end{array}$ \\
\hline
\end{tabular}

Проекты по компьютерному моделированию различных соединений реализовывались на базе биолого-химического факультета Томского государственного педагогического университета совместно с МАОУ гимназией № 18 г. Томска в рамках внеурочной деятельности по химии в течение последних трех лет.

Ниже представлены характеристика и результаты выполнения проекта по теме «Хлориды элементов 15 группы Периодической системы». Данный проект является предметным монопроектом, учебно-исследовательским, индивидуальным и рассчитан на выполнение в течение нескольких месяцев. Соединения элементов 15-й группы периодической системы Д. И. Менделеева являются достаточно интересным объектом изучения с точки зрения квантово-химического расчета. Связано это со сравнительной простотой трехвалентных 
соединений, имеющих только одну неподеленную пару электронов на центральном атоме, с наличием достаточного набора экспериментальных данных, таких как геометрические параметры (длины связей и валентные углы), дипольные моменты, инфракрасные спектры, термодинамические параметры: энтальпия образования, энтропия и т. п.

Ниже приведен пример построения обучающимися молекулярных структур галогенидов соединений 15-й группы и их оптимизации полуэмпирическим методом РМ3, который включает в расчет только валентные электроны. Полученные обучающимися структурные данные исследуемых веществ представлены в табл. 2, там же приведены и экспериментальные данные.

Таблица 2

Экспериментальные и рассчитанные геометрические параметры хлоридов элементов 15-й группь периодической системы Д. И. Менделеева

\begin{tabular}{|c|c|c|c|c|}
\hline Молекула & $\begin{array}{c}\text { Экспериментальная } \\
\text { длина связи }\left(1_{\text {ехр }}\right), \AA\end{array}$ & $\begin{array}{c}\text { Рассчитанная } \\
\text { длина связи } \\
\left(1_{\text {саlс }}\right), \AA\end{array}$ & $\begin{array}{c}\text { Экспериментальный } \\
\text { валентный угол, град. }\end{array}$ & $\begin{array}{c}\text { Рассчитанный } \\
\text { валентный угол, } \\
\text { град. }\end{array}$ \\
\hline $\mathrm{NCl}_{3}$ & 1,759 & 1,718 & 107,1 & 110,7 \\
\hline $\mathrm{PCl}_{3}$ & 2,04 & 2,064 & 100,3 & 99,7 \\
\hline $\mathrm{AsCl}_{3}$ & 2,162 & 2,162 & 98,6 & 99,8 \\
\hline $\mathrm{SbCl}_{3}$ & 2,328 & 2,320 & 97,2 & 97,0 \\
\hline $\mathrm{BiCl}_{3}$ & 2,423 & 2,419 & 97,5 & 100,0 \\
\hline
\end{tabular}

На рис. 1 представлены оптимизированные структуры молекул хлоридов азота, фосфора и мышьяка, из которого видно, что исследуемые молекулы представляют собой тригональные пирамиды с атомами азота, фосфора и мышьяка в вершинах тремя атомами хлора в основаниях пирамид. Из рис. 1 также следует, что в молекулах разные валентные углы.
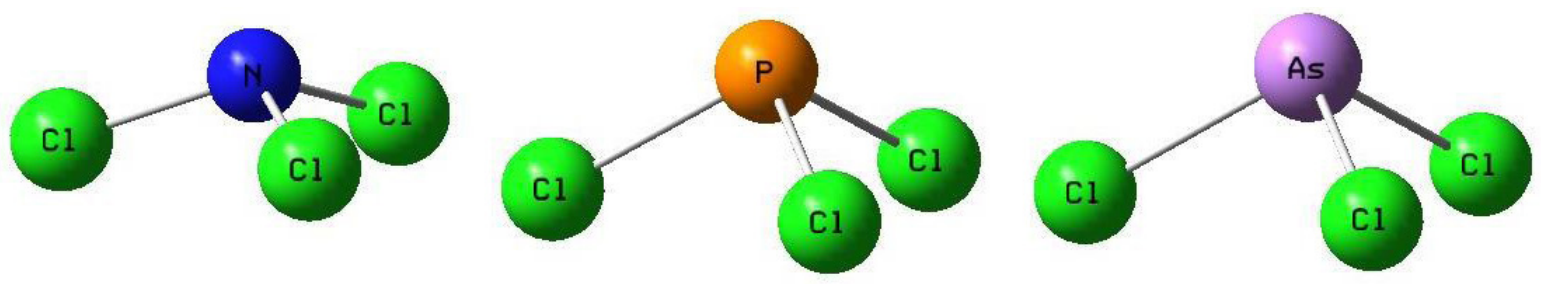

Рис. 1. Оптимизированные структуры молекул хлоридов азота, фосфора и мышьяка

Такое строение молекул объясняется тем, что помимо трех электронов, участвующих в образовании связей, на одной из валентных орбиталей атомов элементов 15-й группы имеется электронный дуплет, не принимающий участия в образовании химической связи. Известно, что неподеленная электронная пара (НЭП) в максимальной степени стремится заполнить пространство вокруг этого атомного остова. Легко убедиться, что при переходе от азота к висмуту больший размер облака НЭП приводят к уменьшению валентных углов Cl-Э-Cl. Расчет, как и эксперимент, показывает аналогичное уменьшение валентного угла одновременно с увеличением длины связи (см. рис. 1, табл. 2).

Для проверки качества расчетов и возможности предсказания экспериментальных значений для новых веществ были построены корреляционные зависимости экспериментальных и рассчитанных значений. Результаты представлены на рис. $2,3$. 


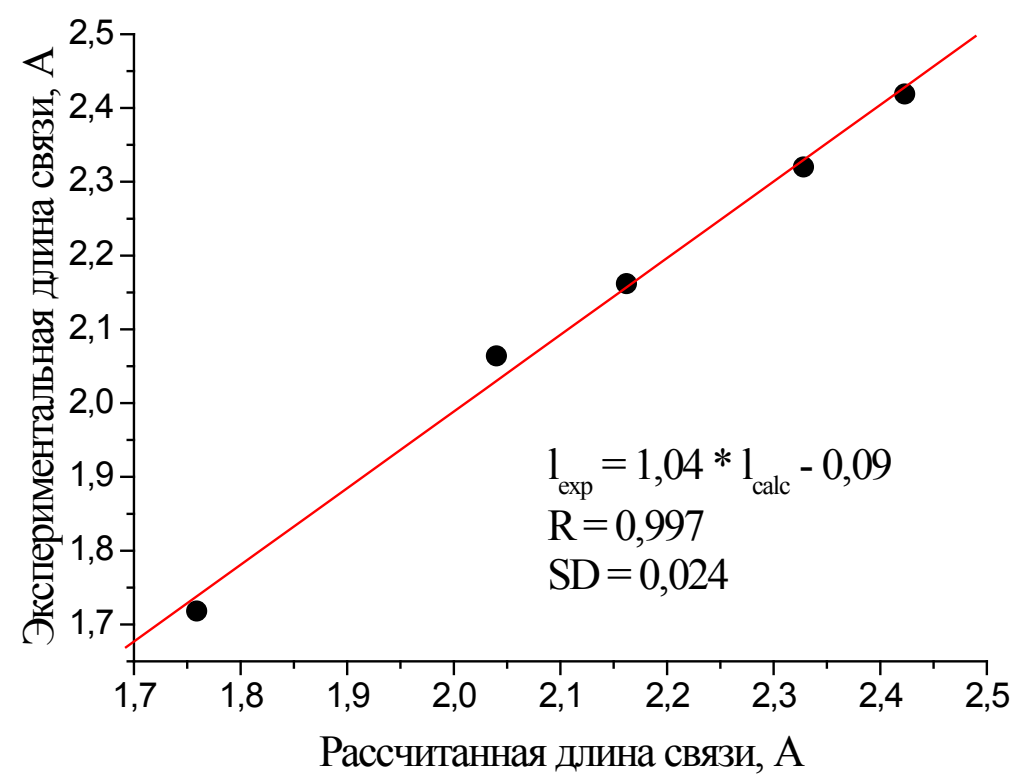

Рис. 2. График корреляционной зависимости между экспериментальными и рассчитанными длинами связей хлоридов элементов 15-й группы

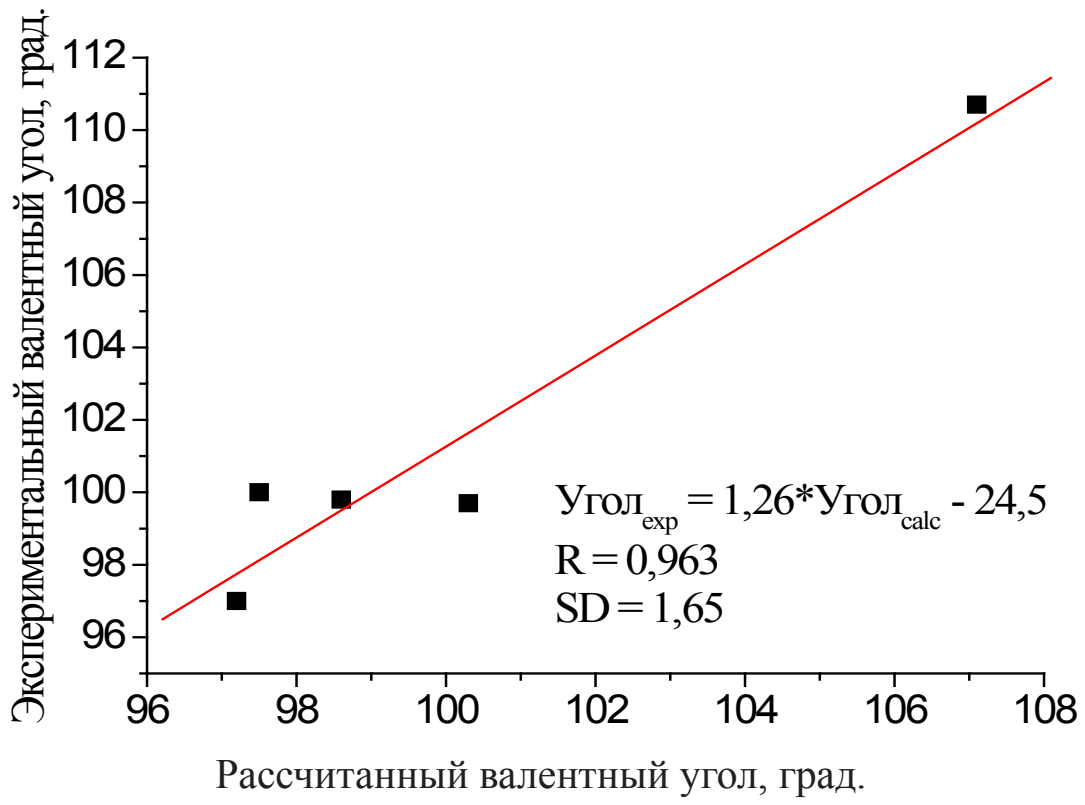

Рис. 3. Графрик корреляционной зависимости между экспериментальными и рассчитанными валентными углами хлоридов элементов 15-й группы

На каждом графике дополнительно приведено уравнение корреляции, указан коэффициент корреляции $(R)$, а также стандартное отклонение $(S D)$. Подставляя в уравнение вычисленное значение исследуемого параметра, можно получить экспериментальное значение с очень хорошей точностью. Качество корреляции характеризуется коэффициентом корреляции $R(0,997$ для длин связей и 0,963 - для валентных углов). Близость коэффициента корреляции к единице указывает на хорошую сходимость расчетных и экспериментальных данных.

Оценивание проекта осуществлялось на основе критериев, разработанных нами (табл. 3). 
Шабанова И. А., Ковалева С. В., Полещук О. Х., Фатеев А. В. Компьютерное моделирование...

Таблица 3

Критерии оценивания проектов, выполняемых обучающимися

\begin{tabular}{|c|c|c|}
\hline Показатели оценки & Критерии оценивания & $\begin{array}{l}\text { Кол-во } \\
\text { баллов }\end{array}$ \\
\hline \multirow{3}{*}{$\begin{array}{l}\text { Теоретическая подготовка для } \\
\text { выполнения проекта }\end{array}$} & Знает материал в полном объеме, не допускает ошибок & 3 \\
\hline & Знает материал, но допускает незначительные ошибки & 2 \\
\hline & $\begin{array}{l}\text { Знает материал поверхностно, допускает существенные } \\
\text { ошибки }\end{array}$ & 1 \\
\hline \multirow{3}{*}{ Доклад по теме проекта } & Материал изложен логично, доступно, речь грамотная & 3 \\
\hline & $\begin{array}{l}\text { Материал изложен логично, доступно, речь грамотная, } \\
\text { но имеются неточности }\end{array}$ & 2 \\
\hline & $\begin{array}{l}\text { Материал изложен поверхностно, с существенными } \\
\text { ошибками, речь не совсем грамотная }\end{array}$ & 1 \\
\hline \multirow{3}{*}{ Презентация } & $\begin{array}{l}\text { Материал презентации соответствует теме проекта, представ- } \\
\text { лен в полном объеме и легко воспринимается аудиторией }\end{array}$ & 3 \\
\hline & $\begin{array}{l}\text { Материал презентации соответствует теме проекта, } \\
\text { но к качеству его представления имеются незначительные } \\
\text { замечания }\end{array}$ & 2 \\
\hline & $\begin{array}{l}\text { Имеются серьезные замечания к содержанию материала } \\
\text { и качеству его презентации }\end{array}$ & 1 \\
\hline \multirow{3}{*}{ Ответы на вопросы } & Ответы правильные и полные & 3 \\
\hline & Ответы правильные, но неполные & 2 \\
\hline & В ответах имеются неточности и существенные ошибки & 1 \\
\hline \multirow{3}{*}{$\begin{array}{l}\text { Умение моделировать молеку- } \\
\text { лы с помощью программы } \\
\text { Gauss View }\end{array}$} & Умеет самостоятельно моделировать молекулы & 3 \\
\hline & $\begin{array}{l}\text { Умеет моделировать молекулы, но иногда требуется помощь } \\
\text { учителя }\end{array}$ & 2 \\
\hline & $\begin{array}{l}\text { Испытывает затруднения при моделировании молекул, } \\
\text { требуется постоянная помощь учителя }\end{array}$ & 1 \\
\hline \multirow{3}{*}{$\begin{array}{l}\text { Умение определять геометри- } \\
\text { ческие параметры построен- } \\
\text { ных молекул }\end{array}$} & $\begin{array}{l}\text { Умеет самостоятельно и правильно определять } \\
\text { геометрические параметры молекул }\end{array}$ & 3 \\
\hline & $\begin{array}{l}\text { Умеет определять геометрические параметры молекул, } \\
\text { но иногда требуется помощь учителя }\end{array}$ & 2 \\
\hline & $\begin{array}{l}\text { Испытывает затруднения при определении геометрических } \\
\text { параметров молекул, требуется постоянная помощь учителя }\end{array}$ & 1 \\
\hline \multirow{3}{*}{$\begin{array}{l}\text { Умение анализировать полу- } \\
\text { ченные результаты }\end{array}$} & Умеет самостоятельно анализировать полученные результаты & 3 \\
\hline & $\begin{array}{l}\text { Умеет самостоятельно анализировать полученные результаты, } \\
\text { но иногда прибегает к помощи учителя }\end{array}$ & 2 \\
\hline & $\begin{array}{l}\text { Испытывает затруднения при анализе полученных результатов, } \\
\text { требуется постоянная помощь учителя }\end{array}$ & 1 \\
\hline
\end{tabular}

После подсчета набранных учеником баллов производился их перевод в оценку по 5-балльной шкале (табл. 4).

Таблица 4

Шкала оценивания

\begin{tabular}{|c|c|}
\hline Кол-во баллов & Оценка \\
\hline $21-19$ & Отлично \\
\hline $18-16$ & Хорошо \\
\hline $15-13$ & Удовлетворительно \\
\hline Менее 13 & Неудовлетворительно \\
\hline
\end{tabular}

Анализируя полученные результаты оценивания проектов, выполняемых в течение трех лет, можно сказать, что все учащиеся успешно справились с заданиями: оценку «отлично» получили 8 человек, «хорошо» - 4 ученика. Качественная успеваемость по выполнению проекта составила $100 \%$.

Кроме того, было проведено анкетирование учащихся, вопросы к анкете приведены в табл. 5. 
Bопросы анкетьл

\begin{tabular}{|c|l|c|}
\hline$№$ п/п & \multicolumn{1}{|c|}{ Bопросы } & Ответ \\
\hline 1 & Имели ли Вы опыт работы с программой GaussView? & $\begin{array}{l}\text { Понравилось ли Вам проводить построение молекул и определять их геометрические } \\
\text { параметры с использованием программы GaussView? }\end{array}$ \\
\hline 3 & Испытывали ли Вы сложности при освоении методики работы с программой GaussView? & \\
\hline 4 & $\begin{array}{l}\text { Испытывали ли Вы сложности при построении соединений, выполняя индивидуальный } \\
\text { проект? }\end{array}$ & $\begin{array}{l}\text { Испытывали ли Вы затруднения при анализе экспериментальных результатов и формули- } \\
\text { ровании выводов? Если «да», то уточните какие }\end{array}$ \\
\hline 6 & Помогла ли Вам в изучении темы «Неметаллы и их соединения» работа над проектом? & \\
\hline 7 & $\begin{array}{l}\text { Помогло ли Вам использование программы GaussView в понимании строения химиче- } \\
\text { ских соединений? }\end{array}$ & \\
\hline 8 & Хотели бы Вы и далее использовать программу GaussView при освоении курса химии? & \\
\hline 9 & $\begin{array}{l}\text { Хотели бы Вы познакомиться с другими подобными программами для моделирования и } \\
\text { строения молекул? }\end{array}$ & \\
\hline
\end{tabular}

Ответы на вопросы анкеты были даны в формате «да» и «нет». На рис. 4 приведены результаты анкетирования.

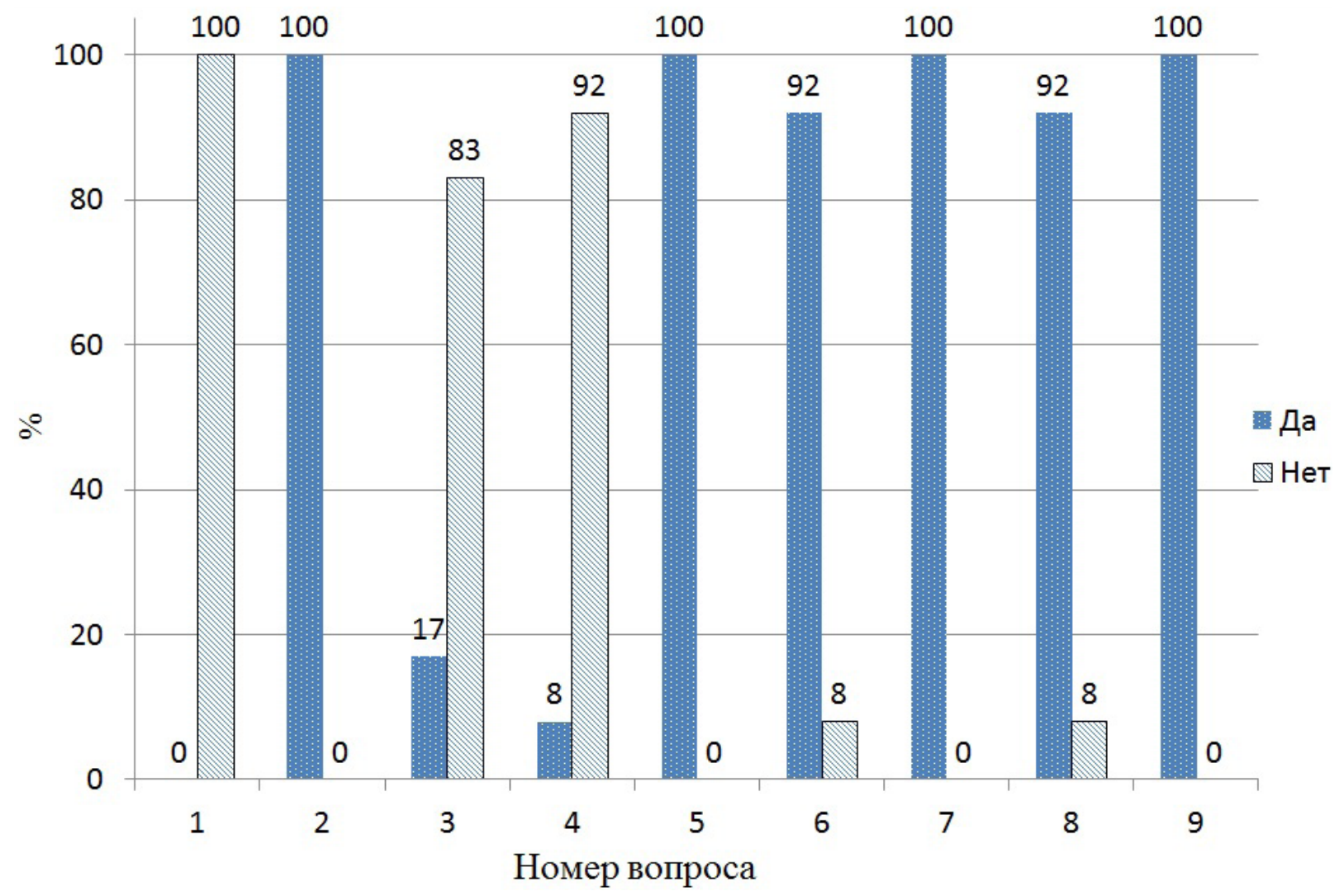

Рис. 4. Результаты анкетирования учащихся

Результаты анкетирования свидетельствуют о том, что все обучающиеся (100%) впервые работали с программой Gauss View и им понравилось моделировать молекулы и определять их геометрические параметры; большинство обучающихся (83\%) не испытывали трудностей при освоении методики работы с программой, а также при построении соединений в индивидуальном проекте (92\%). Основные сложности у респондентов возникли на этапе анализа полученных расчетных и экспериментальных данных и при формулировании выводов (100\%). Работа с программой помогла $92 \%$ анкетируемым в изучении темы 
«Неметаллы и их соединения»; 100 \% респондентов указали, что данная программа помогает лучше воспринимать и понимать строение химических соединений. Большинство анкетируемых (92 \%) выразили желание продолжить исследование с использованием этой программы, а также освоить и другие подобные программы.

Таким образом, в ходе выполнения проекта обучающиеся овладели навыками моделирования молекул различных веществ, проведения расчетов с помощью данной программы, объяснения и анализа полученных результатов и их оформления, что в конечном итоге способствует более глубокому и осознанному пониманию одного из сложных для обучающихся вопроса химии - строения веществ.

Из сказанного выше следует, что работа обучающихся с компьютерными программами по моделированию молекул (ионов) чрезвычайно полезна, так как позволяет им выполнять многочисленные задачи за небольшой промежуток времени и открывает перед ними огромные познавательные возможности, делая их не только наблюдателями, но и активными участниками образовательного процесса. Компьютерное моделирование дает возможность получить геометрические и термохимические характеристики молекул и процессов без проведения многочисленных экспериментов в химических лабораториях.

\section{Список литературы}

1. Письмо Министерства образования и науки РФ от 14.12. 2015 г. № 09-3564 «О внеурочной деятельности и реализации дополнительных общеобразовательных программ». URL: https://www.garant.ru/products/ipo/ prime/doc/71187190/ (дата обращения: 29.11.2019).

2. Методические рекомендации по уточнению понятия и содержания внеурочной деятельности в рамках реализации основных общеобразовательных программ, в том числе проектной деятельности // Вестник образования России. 2017. № 19. С. 25-40.

3. Пак М. С. Теория и методика обучения химии: учеб. для пед. вузов. СПб.: Лань, 2017. С. 246-264.

4. Исаев Д. С., Пак М. С. Современные подходы к организации внеурочной работы с учащимися // Химия в школе. 2018. № 2. С. 54-57.

5. Исаев Д. С., Соболев А. Е. Организация системы работы по химии в соответствии с ФГОС: опыт Тверского района // Актуальные проблемы химического и экологического образования: сб. науч. трудов 63-й Всерос. науч.-практ. конф. СПб.: Изд-во РГПУ им. А. И. Герцена, 2016. С. 20-27.

6. Дьякович С. В., Качалова Г. С. Внеурочная работа по химии в общеобразовательной школе: учеб. пособие. Новосибирск: НГПУ, 1997. 140 с.

7. Внеурочная деятельность. 1-11 классы. Теория и практика: учеб. пособие. СПб.: ВАКО, 2017. 288 с.

8. Григорьев Д. В., Степанов П. В. Внеурочная деятельность школьников. Методический конструктор внеурочной деятельности школьников: пособие для учителя. М.: Просвещение, 2010. 223 с.

9. Исаев Д. С., Соболев А. Е. О подготовке и оценивании итогового проекта // Химия в школе. 2019. № 1. С. 53-58.

10. Пономаренко О. А. Компьютерное моделирование строения органических соединений // Химия в школе. 2019. № 4. C. 38-41.

11. Кец Т. С., Полещук О. Х. Использование программы GAUSS VIEW при проведении занятий по внеурочной деятельности школьников по химии в 9 классах // Сборник материалов XI Международной научно-методической конференции «Преподавание естественных наук, математики и информатики в вузе и школе» (3031 октября 2018 г.). Томск: Изд-во ТГПУ, 2018. С. 208-210.

12. Шабанова И. А., Ковалева С. В., Кадимов Р. Х. Использование компьютерного моделирования на внеурочных занятиях по химии // Преподавание естественных наук, математики и информатики в вузе и школе: сб. материалов ХІІ Междунар. науч.-метод. конф. (30-31 окт. 2019 г.). Томск: Изд-во ТГПУ, 2019. С. 228-231.

13. Сикачина А. А. О пользе освоения учащимися 9-11 профильных классов школ одной из существующих квантово-химических программ // Бюллетень науки и практики. 2019. Т. 5, № 3. С. 439-451.

14. Соловьев М. Е., Соловьев М. М. Компьютерная химия. М.: Соломон-Пресс, 2005. 536 с.

15. Бутырская Е. В. Компьютерная химия: основы теории и работа с программами Gaussian и GausView. M.: Соломон-Пресс, 2011. 224 с. 
16. Полещук О. Х., Кижнер Д. М. Химические исследования методами расчета электронных структур молекул: учеб.-метод. пособие. Томск: Изд-во ТГПУ, 2006. С. 19-25.

17. GAUSSIAN 98W. User's Reference. Pittsburgh, Gaussian Inc., 1998. 280 p.

18. NIST Chemical Database. Standard Reference Database 17, Version 7.0 (Web Version), Release 1.4.2 Data Version 2009.01. URL: http://webbook.nist.gov/chemistry (дата обращения: 20.12.2019).

19. Давыдов В. Н. Теория и методика интегративно-проектного подхода в процессе внеурочной работы по химии: дис. ... д-ра пед. наук. СПб., 2002. 318 с.

20. Особенности метода проектов. URL: https://docplayer.ru/32605063-Osobennosti-metoda-proektov.html (дата обращения: 25.10.2019).

Шабанова Ирина Анатольевна, кандидат педагогических наук, доцент, Томский государственный педагогический университет (ул. Киевская, 60, Томск, Россия, 634061). E-mail: timobix555@yandex.ru

Ковалева Светлана Владимировна, доктор химических наук, профессор, Томский государственный педагогический университет (ул. Киевская, 60, Томск, Россия, 634061). E-mail: svetkovaleva@rambler.ru

Полещук Олег Хемович, доктор химических наук, профессор, Томский государственный педагогический университет (ул. Киевская, 60, Томск, Россия, 634061). E-mail: poleshch@tspu.edu.ru

Фатеев Александр Владимирович, кандидат химических наук, доцент, Томский государственный педагогический университет (ул. Киевская, 60, Томск, Россия, 634061). E-mail: fateevav@tspu.edu.ru

Материал поступил в редакиию 25.12.2019.

DOI 10.23951/2307-6127-2020-2-150-160

\section{COMPUTER MODELING AS ONE OF THE COMPONENTS OF EXTERNAL CHEMISTRY ACTIVITIES AT HIGH SCHOOL}

\section{A. Shabanova, S. V. Kovaleva, O. Kh. Poleshchuk, A. V. Fateyev}

Tomsk State Pedagogical University, Tomsk, Russian Federation

The analysis of the concept of «extracurricular activities» in school education is given, its features are characterized. The concept of «extracurricular activities in chemistry» is given, its purpose and specific feature at the senior level of education in a modern school are highlighted. The necessity of carrying out chemistry projects is substantiated, and one of the relevant areas is proposed: design activities of schoolchildren in modeling the structure of substances. The HyperChem software package, which is used to solve the problems of quantum-mechanical modeling of atomic and molecular structures, is described, which allows performing complex computational problems in chemistry in a short period of time. The methodology of work of schoolchildren with the HyperChem software package is described. The characteristic of individual chemistry projects is given, the stages of their implementation are given. An example of the construction by schoolchildren of the molecular structures of chlorides of elements of group 15 of the periodic system and their optimization by the semiempirical PM3 method, which includes only valence electrons in the calculation, is shown. Correlation dependences of the experimental and calculated bond lengths and bond angles, correlation equations, correlation coefficients $(R)$, and standard deviation $(S D)$ are presented. 
The results of evaluating completed projects on the basis of developed criteria, assessment scales and student performance on completed projects are presented. Questions were developed for questioning students in order to determine their attitude to the GaussView program.

Keywords: extracurricular activities in chemistry, project activities, stages of the project, project evaluation, computer simulation, quantum-chemical calculations.

\section{References}

1. Pis'mo Ministerstva obrazovaniya i nauki RF ot 14.12. 2015 g. № 09-3564 "O vneurochnoy deyatel'nosti $i$ realizatsii dopolnitel'nykh obshcheobrazovatel'nykh programm" [Letter of the Ministry of Education and Science of the Russian Federation of 14.12. 2015 No. 09-3564 "On extracurricular activities and the implementation of additional general education programs"] (in Russian). URL: https://www.garant.ru/products/ipo/prime/ doc/71187190/ (accessed 29 November 2019).

2. Metodicheskiye rekomendatsii po utochneniyu ponyatiya i soderzhaniya vneurochnoy deyatel'nosti v ramkakh realizatsii osnovnykh obshcheobrazovatel'nykh programm, v tom chisle proektnoy deyatel'nosti [Guidelines for clarifying the concept and content of extracurricular activities in the framework of the implementation of basic general educational programs, including project activities]. Vestnik obrazovaniya Rossii, 2017, no. 19, pp. $25-40$ (in Russian).

3. Pak M. S. Teoriya i metodika obucheniya khimii: uchebnik dlya pedagogicheskikh vuzov [Theory and methodology of teaching chemistry: a textbook for pedagogical universities]. Saint Petersburg, Lan' Publ., 2017. Pp. 246-264 (in Russian).

4. Isayev D. S., Pak M. S. Sovremennye podkhody k organizatsii vneurochnoy raboty s uchashchimisya [Modern approaches to the organization of extracurricular work with students]. Khimiya v shkole, 2018, no. 2, pp. 54-57 (in Russian).

5. Isayev D. S., Sobolev A. E. Organizatsiya sistemy raboty po khimii v sootvetstvii s FGOS: opyt Tverskogo rayona [Organization of a chemistry work system in accordance with Federal State Educational Standard: experience of the Tver region]. Aktual'nye problemy khimicheskogo i ekologicheskogo obrazovaniya: Sbornik nauchnykh trudov 63-y Vserossiyskoy nauchno-prakticheskoy konferentsii [Actual problems of chemical and environmental education: Collection of scientific papers of the 63rd Russian National Scientific and Practical Conference]. Saint Petersburg, Herzen State Pedagogical University of Russia Publ., 2016. Pp. $20-27$ (in Russian).

6. D'yakovich S. V., Kachalova G. S. Vneurochnaya rabota po khimii v obshcheobrazovatel'noy shkole: uchebnoye posobiye [Extracurricular work in chemistry at a comprehensive school: a training manual]. Novosibirsk, NSPU Publ., 1997. 140 p. (in Russian).

7. Vneurochnaya deyatel'nost'. 1-11 klassy. Teoriya i praktika: uchebnoye posobiye [Extracurricular activities. Grades 1-11. Theory and Practice: A Study Guide]. Saint Petersburg, VAKO Publ., 2017. 288 p. (in Russian).

8. Grigor'yev D. V., Stepanov P. V. Vneurochnaya deyatel'nost'shkol'nikov. Metodicheskiy konstruktor vneurochnoy deyatel'nosti shkol'nikov: posobiye dlya uchitelya [Extracurricular activities of schoolchildren. The methodical designer of extracurricular activities of schoolchildren: a manual for the teacher]. Moscow, Prosveshcheniye Publ., 2010. 223 p. (in Russian).

9. Isayev D. S., Sobolev A. E. O podgotovke i otsenivanii itogovogo proyekta [On the preparation and evaluation of the final project]. Khimiya $v$ shkole, 2019, no. 1, pp. 53-58 (in Russian).

10. Ponomarenko O. A. Komp'yuternoye modelirovaniye stroyeniya organicheskikh soyedineniy [Computer simulation of the structure of organic compounds]. Khimiya $v$ shkole, 2019, no. 4, pp. 38-41 (in Russian).

11. Kets T. S., Poleshchuk O. Kh. Ispol'zovaniye programmy GAUSS VIEW pri provedenii zanyatiy po vneurochnoy deyatel'nosti shkol'nikov po khimii 9 klassakh [Use of the GAUSS VIEW program during classes on extracurricular activities of schoolchildren in chemistry in grades 9]. Sbornik materialov XI Mezhdunarodnoy nauchnometodicheskoy konferentsii "Prepodavaniye estestvennykh nauk, matematiki informatiki v vuze i shkole" [Collection of materials of the XI International Scientific and Methodical Conference «Teaching of natural sciences, mathematics and computer science in high school and school»]. Tomsk, TSPU Publ., 2018. Pp. 208-210 (in Russian).

12. Shabanova I. A., Kovaleva S. V., Kadimov R. Kh. Ispol'zovaniye komp'yuternogo modelirovaniya na vneurochnykh zanyatiyakh po khimii [The use of computer modeling in extracurricular chemistry classes]. Sbornik materialov XII Mezhdunarodnoy nauchno-metodicheskoy konferentsii "Prepodavaniye estestvennykh nauk, matematiki i informatiki v vuze i shkole" [Collection of materials of the XI International Scientific and Methodical Conference «Teaching of natural sciences, mathematics and computer science in higher school and school»]. Tomsk, TSPU Publ., 2019. Pp. 228-231 (in Russian). 
13. Sikachina A. A. O pol'ze osvoyeniya uchashchimisya 9-11 profil'nykh klassov shkol odnoy iz sushchestvuyushchikh kvantovo-khimicheskikh programm [The benefits of mastering by students of 9-11 specialized classes of schools of one of the existing quantum chemical programs]. Byulleten' nauki $i$ praktiki - Bulletin of Science and Practice, 2019, vol. 5, no. 3, pp. 439-451 (in Russian).

14. Solov'ev M. E., Solov'ev M. M. Komp'yuternaya khimiya [Computer chemistry]. Moscow, Solomon-Press Publ., 2005. 536 p. (in Russian).

15. Butyrskaya E. V. Komp'yuternaya khimiya: osnovy teorii i rabota s programmami Gaussian i GausView [Computer chemistry: fundamentals of theory and work with Gaussian and GausView programs]. Moscow, Solomon-Press Publ., 2011. 224 p. (in Russian).

16. Poleshchuk O. Kh., Kizhner D. M. Khimicheskiye issledovaniya metodami rascheta elektronnykh struktur molekul: uchebno-metodicheskoye posobiye [Chemical studies by methods of calculating the electronic structures of molecules: educational-methodical manual]. Tomsk, TSPU Publ., 2006. Pp. 19-25 (in Russian).

17. GAUSSIAN 98W. User's Reference. Editors Fritsch E., Fritsch M. J., Pittsburgh, Gaussian Inc. 1998. 280 p.

18. NIST Chemical Database. Standard Reference Database 17, Version 7.0 (Web Version), Release 1.4.2 Data Version 2009.01. URL: http://webbook.nist.gov/chemistry (accessed 20 December 2019).

19. Davydov V. N. Teoriya i metodika integrativno-proektnogo podkhoda v protsesse vneurochnoy raboty po khimii. Dis. d-ra ped. nauk [Theory and methodology of the integrative-design approach in the process of extracurricular work in chemistry. Dis. of doct. ped. sci.]. Saint Petersburg, 2002. 318 p. (in Russian).

20. Osobennosti metoda proyektov [Features of the project method] (in Russian). URL: https://docplayer.ru/32605063Osobennosti-metoda-proektov.html (accessed 25 October 2019).

Shabanova I. A., Tomsk State Pedagogical University (ul. Kiyevskaya 60, Tomsk, Russian Federation, 634061). E-mail: timobix555@yandex.ru

Kovaleva S. V., Tomsk State Pedagogical University (ul. Kiyevskaya 60, Tomsk, Russian Federation, 634061). E-mail: svetkovaleva@rambler.ru

Poleshchuk O. Kh., Tomsk State Pedagogical University (ul. Kiyevskaya 60, Tomsk, Russian Federation, 634061). E-mail: poleshch@tspu.edu.ru

Fateyev A. V., Tomsk State Pedagogical University (ul. Kiyevskaya 60, Tomsk, Russian Federation, 634061). E-mail: fateevav@tspu.edu.ru 